Sciendo

\title{
Of Counterfeits and Delusions: \\ Revisiting Ryle on Skepticism and the Impossibility of Global Deceit \\ Douglas McDermid \\ Trent University
}

Disputatio Vol. 1, No. 17

November 2004

DOI: $10.2478 /$ disp-2004-0010

ISSN: 0873-626X 


\title{
Of counterfeits and delusions: Revisiting Ryle on skepticism and the impossibility of global deceit
}

\author{
Douglas McDermid \\ Trent University
}

\begin{abstract}
To think the skeptic overlooks something obvious, to attribute to him a simple mistake or confusion or fallacy, is to refuse to acknowledge the power of his position and the grip it can have upon us. We thereby cheat ourselves of the opportunity to reap his insights and to gain selfknowledge in understanding why his arguments lure us so.
\end{abstract}

Robert Nozick $(1981,197)$

\begin{abstract}
Consider the following proposition: (Q) It is possible that all of our perceptual experiences are 'delusive.' According to Gilbert Ryle, (Q) is demonstrably absurd. In this paper I address four questions: (1) What is Ryle's argument against $(\mathrm{Q})$ ?; (2) How persuasive is it?; (3) What positions are ruled out if $(\mathrm{Q})$ is absurd?; and (4) How does Ryle's position compare with contemporary work on skepticism?
\end{abstract}

\subsection{Introduction: Ryle and epistemology}

Gilbert Ryle and epistemology? Surely that conjunction has a decidedly odd, even perverse ring to it - as if it were one of those infamous category mistakes against which Ryle inveighed with such panache. ${ }^{1}$ Let me immediately reassure the reader, however, that I have no intention of contesting either of the following platitudes in this essay: (i) first, that Ryle's most important work lies not in epistemology, but

${ }^{1}$ On the notion of a category mistake, see Ryle (1949, 17-20); cf. Ryle (1938).

Disputatio, Vol. I, No. 17, November 2004 
in the areas of the philosophy of mind, philosophical psychology, metaphilosophy and - somewhat more controversially - Plato scholarship ${ }^{2}$ and (ii) second, that Ryle was certainly not an 'epistemologist' in the sense in which that honorific epithet can be applied to, say, Ayer, C.I. Lewis, Sellars, Chisholm, Goldman, Plantinga, or Sosa; for Ryle advances nothing that could be sensibly described as a 'theory' of knowledge. ${ }^{3}$

Let us grant (i) and (ii), I say - by all means. Nevertheless, it is still a matter of public record that Ryle had novel and provocative things to say about a host of matters standardly classified as epistemological; these include sense-perception, verification, the distinction between 'knowing how' and 'knowing that,' the nature of self-knowledge, and the problem of other minds. ${ }^{4}$ In this essay, I shall ponder and weigh some of what Ryle had to say about another epistemological thesis: that of Cartesian-style global skepticism. Since this is an issue which continues to vex and exercise philosophers, Ryle's bold attempt to debunk skepticism is not of merely historical or antiquarian interest and yet it still has not received anything like the critical attention it deserves. ${ }^{5}$ Let us see, then, what epistemologists can learn by scrutinizing Ryle's reflections on global skepticism.

\footnotetext{
${ }^{2}$ For Ryle's work in the philosophy of mind and philosophical psychology, see Ryle (1949), (1953a), (1958), (1962a), (1962b), (1968), (1979); for his work on metaphilosophy, (1932b), (1936), (1937), (1938), (1945), (1950), (1953b), (1954), (1954a), (1970); and for the work on Plato, see Ryle (1939), (1960), (1965a), (1965b), (1965c), (1966).

${ }^{3}$ Nor, it seems, was Ryle in a position to do so, since the standard formulations of many of the central problems of epistemology presuppose the broadly Cartesian conception of the mind and its contents he denounced in The Concept of Mind; cf. Ryle (1949, 212-213), for a good example of this. This sense - that the cluster of traditional issues (including that of skepticism) with which epistemologists have been preoccupied are ill-posed or otherwise suspect - was shared by other figures often indiscriminately lumped together under the vague rubric of 'ordinary language philosophy'; cf. Wisdom (1936), (1946); Austin (1946, 98), (1962, 124); Bouwsma (1946); Malcolm (1963); Wittgenstein (1969); and Cavell (1979).

${ }^{4}$ Cf. Ryle (1932a); (1936); (1946); (1949), Chapters II, VI, VII, and IX; (1950); (1956). An overview can be found in Bird (1992).

${ }^{5}$ Indeed, the argument has been ignored in the recent literature on skepticism. For instance, Stroud (1984), Williams (1996), and Greco (2000) all insightfully examine a remarkably wide range of critical responses to skepticism, but none of them so much as mentions Ryle's attempt to debunk skepticism. There are a few authors who have discussed Ryle's argument - see Bird (1992), as well as Grayling
} 


\subsection{Ryle and the skeptical argument from fallibility}

In Dilemmas, Ryle scouts a familiar argument for skepticism, namely, 'the quite general argument from the notorious limitations and fallibilities of our senses to the impossibility of our getting to know anything at all by looking, listening and touching' (Ryle 1954, 94; cf. 98). According to Ryle, this sort of argument has long been popular with philosophers of radically divergent outlooks who yearn to discredit the testimony of our senses:

Thinkers who wish to maintain the pre-eminence of mathematical knowledge over other beliefs, and thinkers who wish to depreciate mundane beliefs in favour of supra-mundane beliefs have often argued from these notorious facts of illusion, delusion and imprecision in sense perception to the sweeping conclusion that we can never find out anything for certain by using our eyes, ears and noses (Ryle 1954, 94).

Let us call the skeptical argument Ryle targets the Argument from Fallibility. Although Ryle does not deign to name names or identify any of its proponents or partisans, ${ }^{6}$ his sin of omission is of little or no consequence for two reasons: (i) Ryle cannot be accused of demolishing a strawman of his own invention, since the Argument from Fallibility - or something approximating it - can be plausibly attributed to rationalists such as Plato and Descartes as well as to fideists such as Montaigne; and (ii) far from being elusive and inscrutable, the argument's basic logical structure is easily descried. For the Argument from Fallibility starts from a simple and seemingly uncontroversial premise, $(\mathrm{P})$

(P) Some perceptual experiences are non-veridical or 'delusive' (i.e. they do not get reality right). ${ }^{7}$

(1985), (1992) - but these discussions are brief and much less detailed than what is offered in this paper.

${ }^{6}$ Anthony Quinton has observed that this reticence to name names is characteristic of Ryle's work, in which '[o]ther philosophers are seldom mentioned by name and even less often quoted. The positions criticised are not precisely and historically identified' (Quinton 1970, 105).

${ }^{7}$ Seemingly uncontroversial, I say, because its precise formulation raises at least three difficulties: (i) Premise (P) has often been formulated using the metaphor of deception, but such lax anthropomorphizing talk - the epistemologist's version of the pathetic fallacy? - can encourage certain misunderstandings, as Ryle (1954, 98- 
and arrives (albeit with the aid of a battery of supplementary assumptions) at the strikingly counterintuitive conclusion, (C):

(C) Our senses cannot yield knowledge of the external world (e.g - that you are seated by the fire, that here is one hand and here is another, that there is a blue chair in yonder corner or cheese on the table, etc.) .

Faced with the chore of commenting on this unpromising argument, many philosophers would content themselves, first, with observing that $(\mathrm{P})$ on its own does not entail $(\mathrm{C})$; and second, with working assiduously to undermine whatever bridge assumptions the skeptic desperately introduces to span the logical chasm between $(\mathrm{P})$ and $(\mathrm{C})$. But such a flat-footed style of commentary is not Ryle's way; the route he travels is less plodding and pedestrian, but more scenic and adventurous - and, not coincidentally, more circuitous and harder to follow. For although Ryle denies the skeptical conclusion, (C), he does not attack it directly. Instead, he concentrates his critical fire on the following skeptical-sounding proposition, (Q):

(Q) It is possible that all of our perceptual experiences are non-veridical or 'delusive.'

According to Ryle, (Q) is demonstrably absurd: it simply could not be the case that all our perceptual experiences were non-veridical or delusive.

\subsection{Four questions about Ryle's project}

Now, there are four interconnected questions about Ryle's putative refutation of (Q) I should like to address in this essay:

1. The Interpretative Issue: What, exactly, is Ryle's argument against (Q)?

99) and Austin (1962, 8-9; 11-13) both observed; (ii) Some philosophers would object to $(\mathrm{P})$ as it stands on the grounds that the senses per se cannot err; it is only our beliefs or judgments about what we see, feel, taste, touch and smell that can be faulted; and (iii) The very term 'delusive' may itself have misleading implications; cf. Austin $(1962$, 22-26). All these issues are worthy of serious consideration, but we can safely ignore them here. Ryle is evidently prepared to accept (P), and his opposition to (Q) is not nourished or fed by any of the aforementioned scruples. 
2. The Evaluative Issue: Has Ryle given us reason to suppose that (Q) is absurd, that is, that not all of our perceptual experiences can be non-veridical or delusive?

3. The Epistemological Issue: Suppose (Q) is not true; what epistemological positions would that rule out? (For instance, would we then be entitled to conclude that $(\mathrm{C})$ - the skeptical thesis - is false?)

4. The Relevance Issue: How does Ryle's position compare with contemporary work on skepticism?

The essay's plan is straightforward. Issue (1) is addressed in Section 2; issue (2), in Section 3.1 and 3.2; issue (3), in Section 4; and issue (4) in Sections 3.3 and 5. Section 6 summarizes our main conclusions.

\subsection{Ryle's argument against global deceit: an overview}

Ryle's response to the skeptical Argument from Fallibility begins with a curious (because seemingly stray and unrelated) observation, namely, that if there are counterfeit coins in circulation, there must also be such a thing as legal tender - that is, some standard or valid official currency of which the counterfeit coins are spurious and illicit reproductions. He writes:

A country which had no coinage would offer no scope for counterfeiters. There would be nothing for them to manufacture or pass counterfeits of. They could, if they wished, manufacture and give away decorated discs of gold or brass, which the public might be pleased to get. But these would not be false coins. There can be false coins only where there are coins made of proper materials by the proper authorities.

In a country where there is a coinage, false coins can be manufactured and passed; and the counterfeiting might be so efficient that an ordinary citizen, unable to tell which were false and which genuine coins, might become suspicious of the genuineness of any particular coin that he received. But however general his suspicions might be, there remains one proposition he cannot entertain, the proposition, namely, that it is possible that all coins are counterfeits. For there must be an answer to the question: 'Counterfeits of what?' (Ryle 1954, 94-95).

Using this crucial passage as our guide, we must now (a) extract from it Ryle's argument against the proposition that all coins could be counterfeit, then (b) formulate a parallel argument for the conclusion that not all perceptual experiences could be delusive or non-veridical. 
Here, then, is an elementary reconstruction of Ryle's argument concerning counterfeit coins.

Argument (a): The Coin Argument

a1. There cannot be false or counterfeit coins unless there are genuine coins.

Therefore,

a2. Not all coins can be false or counterfeit: if some are fakes, others must be genuine. [From a1]

We are then invited to suppose that what holds in the case of the counterfeit / genuine contrast holds also in the case of the contrast between delusive and veridical perceptual experiences, and argue accordingly:

Argument (b): The Perception Argument

b1. There cannot be delusive (or non-veridical) perceptual experiences (DPEs) unless there are veridical perceptual experiences (VPEs).

Therefore,

b2. Not all perceptual experiences can be delusive: if there are DPEs, there must also be VPEs. [From b1; incompatible with (Q).]

Since (b2) follows unproblematically from (b1), everything depends on whether the latter premise is true. However, Ryle's precise reasons for endorsing (b1) remain obscure: he expounds the parable of the counterfeit coins and then leaves us to puzzle out the case of DPEs for ourselves. $^{8}$ As with certain other parables, then, the implied message

${ }^{8}$ This is not terribly surprising, given the aptness of Daniel Dennett's recent description of Ryle's method as 'exasperating informal, not just a-systematic but positively anti-systematic, the brilliant piling on of analogies and examples and rhetorical flourishes, cunningly designed to cajole the reader out of those bad habits of thought, a sort of philosophical guerilla warfare that never settles into or commits to a positive 'theory' for long enough to permit a well-aimed attack' (Dennett 2000, xii). 
here seems to be: Those who have ears, let them hear. Very well; but what reason is there to accept (b1)?

\subsection{A tale of two arguments}

Let us now examine two arguments by means of which one might try to secure premise (b1). I shall dub the first of these ways 'The Argument from Standards'; the second, 'The Argument from Meaning.'

\subsection{The argument from standards}

'Counterfeits of what?' queries Ryle at the end of the passage cited above in Section 2 (Ryle 1954, 95). His point is well-taken: since counterfeits evidently must be counterfeits of something, their manufacture presupposes a standard from which they deviate, that is, some original of which they are copies, reproductions, or simulacra. Suppose, then, that Ryle's point is that DPEs, like counterfeits, presuppose a normative standard of correctness from which they depart. Here is one way of developing this intuition:

The Argument from Standards

S1. To say that there are DPEs is to say that there are PEs that do not get reality right.

S2. But this talk of not getting reality right assumes that there is something there to get right or to represent accurately (i.e. - some fact of the matter, or a way objects actually are).

S3. Now, VPEs are PEs that get reality right or accurately represent the ways objects are.

Therefore,

\section{S4. There cannot be DPEs unless there are VPEs. [S1-S3]}

The Argument from Standards does not hold up very well under scrutiny, however. Of the argument's three premises, (S1) and (S3) seem the least controversial, inasmuch as they merely profess to unpack what is meant by the terms 'delusive' and 'veridical,' respectively. But - a critic will naturally ask - why accept premise (S2)? That is, why could not we allow there are DPEs without thereby being compelled to admit the existence of external objects of perception? 
Suppose a form of solipsism is true according to which nothing exists aside from S's mind and its contents. In such a case, there exists nothing outside of S's mind which S's experiences can misrepresent. Nevertheless, some would be loath to admit that any of S's experiences count as veridical in any non-Pickwickian sense of the term. (Why? Here is one reason. Suppose an experience qualifies as veridical only if it represents some external object or state of affairs that is intersubjectively available, that is, not epistemically private but available in principle to some subject other than S. If solipsism is true, however, there cannot be a subject other than $\mathrm{S}$ and there cannot be such objects). But if none of the solipsist's PEs can qualify as veridical, then talk of PEs not getting reality right does not necessarily commit us to saying that there is something out there which PEs can get right, or represent accurately. ${ }^{9}$ And in that case, (S2) would be false.

Yet let us waive this difficulty and consider a far more serious problem facing the Argument from Standards - namely, the fact that it is invalid, because what follows from premises (S1)-(S3) is a claim decidedly weaker than (S4). From (S1) and (S2), we can infer no more than that DPEs imply there is something - a way the objects of perception are - which DPEs misrepresent. Even if we grant it must be possible in principle for some PEs to represent accurately what DPEs misrepresent, all we can conclude from the conjunction of this claim with (S3) is that there cannot be DPEs unless VPEs are possible. But that is not, of course, to say that there actually are any VPEs, or that there must be VPEs if there are DPEs. In order to make sense of DPEs, then, we need only assume there is a way things are, not that any PEs represent it correctly.

Here, it seems, the Rylean parallel between counterfeits and DPEs breaks down in a striking way. The difference between the two cases can be spelled out as follows. In both scenarios, we are confronted with items (coins, PEs) with a certain peculiar property or attribute (that of being counterfeit, or delusive), and told that there cannot be items of that sort - let us call them 'fakes' - unless there is some

${ }^{9}$ But talk of getting reality wrong, or of misrepresenting it, does commit us to saying this; for then we have assumed there is, as it were, a real target out there we have missed. Can we not then sidestep this objection by stipulating that all we are talking about are the perceptual equivalent of 'misses'? Unfortunately, that will not help: as long as it is allowed that one way in which a PE can be a DPE is when there is no object corresponding to it which it misrepresents, we cannot conclude that the existence of DPEs means there must be external objects of perception. 
standard (i.e. - that of legal tender, or veridicality) from which these fakes deviate or depart. So far, so good. However, whereas we have just been given reason to think that the relevant standard of correctness need not be embodied in items of the same type as the fakes if the fakes in question are DPEs, it seems that standard must be (or have been) embodied or instantiated in items of the same type as the fakes if the fakes are counterfeit coins; for acknowledging the existence of counterfeits commits us to more than the bare possibility of legal tender ever existing. As Ryle himself points out, 'there must be an answer to the question: 'Counterfeits of what?" (Ryle 1954, 95). And that answer will involve a story about actual or real money; for ' $[\mathrm{t}]$ here can be false coins only where there are coins made of proper materials by the proper authorities' (Ryle 1954, 94).

\subsection{The argument from meaning}

Even if the Argument from Standards fails, Ryleans might still be able to defend (b1). For - to return to the case of counterfeits - note the following: if there were no such things as genuine coins, it would arguably make no sense to speak of counterfeits (i.e. - in that case, a statement to the effect that there were counterfeits would not be false, strictly speaking, but meaningless or devoid of cognitive content). So perhaps the basic idea underlying (b1) is that talk of DPEs is nonsense - mere sound and fury signifying nothing - unless there are VPEs. And that leads us to consider the following argument for (b1):

The Argument from Meaning

M1. We cannot understand (make sense of) talk of DPEs unless there are VPES.

M2. If no PEs were VPEs, $(\mathrm{P})$ would be meaningless (i.e. - we could never say that some PEs were DPEs). [M1]

$\mathrm{M} 3$. But $(\mathrm{P})$ is not meaningless or nonsensical.

Therefore,

M4. Not all PEs are DPEs; some must be VPEs. [M2, M3]

We may classify the Argument from Meaning as a transcendental argument, provided we agree that such arguments are structured around the premise that some admittedly actual phenomenon, $\mathrm{X}$, is 
possible only if some non-trivial condition, $\mathrm{Y}$, is satisfied. ${ }^{10}$ Here ' $\mathrm{X}$ ' is our understanding or grasp of the very idea of a DPE; 'Y', the existence of VPEs.

Unlike the Argument from Standards, the Argument from Meaning is formally valid: (M4) follows from (M3) and (M2); and (M2) can be derived from (M1). Furthermore, those partial to the Argument from Fallibility are plainly in no position to quarrel with premise (M3) (which certainly seems true in any case). Should we also accept (M1) and aver that the very idea of a DPE is unintelligible unless there are VPEs?

Consider the following argument, the all-important second premise of which is strongly suggested by remarks Ryle makes about how mistakes are made and exposed. ${ }^{11}$

The Detection Argument for M1

1. DPE is a species of mistake or error.

2. But it is senseless for us to speak of errors that no-one could ever detect. $^{12}$

3. Therefore, it makes sense to speak of DPEs only if it is possible (at least in principle) to detect them. [1, 2]

4. But that is impossible unless there are VPEs with which DPEs can be compared and contrasted.

Therefore,

5. Talk of DPEs make no sense - is meaningless or empty - unless there are VPEs. [3, 4; equivalent to M1].

Predictably, certain realist philosophers - Thomas Nagel is an contemporary outstanding example ${ }^{13}$ - will immediately complain that the Detection Argument is vitiated by its reliance on the verificationist assumptions about meaning that underwrite premise (2). But if the

\footnotetext{
${ }^{10}$ On transcendental arguments, see Stroud (1968); Taylor (1972); and Grayling (1992), who recognizes Ryle's argument as one.

${ }^{11}$ Ryle (1954, 95-96); the examples Ryle uses involve counting, adding, and proofreading.

${ }^{12}$ For an extended development of this point, see Bouwsma (1946), especially the distinction between 'thin illusions' and 'thick illusions' (Bouwsma 1946, 95). Cf. Austin (1962, 118-119); Wittgenstein (1969, §3, §56, §200).

${ }^{13}$ Cf. Nagel $(1986,73)$.
} 
Detection Argument is unsound, what reason is there to endorse (M1)? None, these critics will plead, unless another, nonverificationist argument is forthcoming (and none is in plain sight in Ryle). Accordingly, some will conclude that the case against (Q) has simply collapsed. But let us not be too hasty: suppose that (pace Nagel and company) verificationism is correct, in which case the philosophical skeptic's claim that there is enigmatic 'External World' about which we can know nothing may be written off as senseless or unintelligible. ${ }^{14} \mathrm{~A}$ resounding victory for Ryle, you say? Again, not so fast: if verificationism can get rid of the Cartesian skeptic on its own, it is no longer necessary to bother with the Argument from Fallibility or with $(\mathrm{Q})$, as Ryle does. It would therefore appear that invoking verificationism to prop up (M1) would render much of what Ryle has to say otiose or unnecessary.

So there is a basic dilemma we are constrained to acknowledge. If verificationism is not true, the Detection Argument for (M1) is unsound; but in that case the Argument from Meaning fails to carry conviction (since its key premise lacks support). If verificationism is true, however, we can dismiss skepticism without recourse to (M4); verificationism alone will suffice for that. ${ }^{15}$ As things stand, then, the Argument from Meaning seems either inconclusive or superfluous.

\subsection{The argument from meaning and Putnam on brains in vats}

Before we bid a fond adieu to the Argument from Meaning, we should note the ingenious anti-skeptical strategy it exploits, viz., that it must be case that a certain skeptical possibility (i.e. - that of global deceit or error) does not obtain, for if it obtained we would be unable to talk about it or understand descriptions of it. The same basic strategy underlies Hilary Putnam's much more recent contention that if you can meaningfully say or think that 'I am a brain in a vat,' then you cannot be a brain in a vat; for, according to Putnam, if you were actually a brain in a vat, the conditions necessary for your words to refer to things like brains and vats would not be satisfied. ${ }^{16}$ This parallel means that if the Argument from Meaning accurately reflects

${ }^{14}$ Cf. Stroud (1984), Chapter 5.

${ }^{15}$ Cf. Stroud (1968) on the verificationism implicit in certain transcendental arguments with anti-skeptical pretensions.

${ }^{16}$ Cf. Putnam (1981), Chapter 1. 
Ryle's intentions, then he can be credited with anticipating an idea central to Putnam's celebrated and influential anti-skeptical argument.

Nevertheless, there are important differences between the two arguments. Here I shall just mention two:

(i) First, Putnam's argument is much more philosophically ambitious than Ryle's, inasmuch as the former's reply to the skeptic flows from his answer to a deep philosophical question - namely, that of how intentionality is possible, or (less grandiosely) that of how thought and language can represent or refer to reality. Represented schematically, Putnam's anti-skeptical strategy can be profitably divided into two parts. First, he identifies the preconditions of reference (i.e. - he urges that ' $[0]$ ne cannot refer to certain kinds of things, e.g. trees, if one has no causal interaction at all with them' (Putnam $1981,16))$. Second, he argues that if the skeptical 'Brain in a Vat' (BIV) hypothesis actually obtained, the preconditions for reference would not be satisfied (i.e. - if I were a BIV, I would not be related to brains and vats in a way that would enable me to refer to such things). From this Putnam infers that the BIV scenario is self-refuting: 'brains in a vat cannot think or say that they are brains in a vat' (Putnam 1981, 14). Ryle, in contrast, does not essay anything like a general account of how thought or reference überhaupt are possible. Accordingly, his attack on (Q) cannot be represented as a corollary of such an account or theory.

(ii) If our first observation seems to favour Putnam's argument over Ryle's, our second observation calls attention to an important respect in which Ryle's argument may be superior to Putnam's, if both are construed as replies to skepticism. For whereas Ryle's argument is wholly a priori, Putnam's is not (as Putnam himself cheerfully avows). As it happens, this second point of contrast is bound up with the first: it obtains because Putnam, whose project requires him to specify the preconditions of reference, maintains that said preconditions are 'not (as Kant hoped) wholly independent of empirical assumptions' (Putnam 1981, 16). But the skeptic will be decidedly unimpressed by would-be refutations which rest on empirical assumptions, or any claims about the way the world is; indeed, he will take Putnam to task for begging the question. ${ }^{17}$

\footnotetext{
${ }^{17}$ Hymers $(2000$, 26-27) for discussion of the significance of this feature of Putnam's argument.
} 


\subsection{Implications}

The chief moral of Sections 3.1 and 3.2 is plain enough: neither the Argument from Standards nor the Argument from Meaning is unassailable. Nevertheless, let us suppose - if only for the sake of argument - that Ryle is right and that (Q) cannot be true. What would follow? What are the implications of (b2)?

\subsection{A (very) modest proposal}

Let me call attention to the breathtaking modesty of Ryle's conclusion by directing the reader's attention to five key theses (b2) does not rule out.

(i) First, (a2) says there cannot be counterfeits without legal tender; but it does not say we can tell them apart. Similarly, (b2) does not say that we can distinguish VPEs from DPEs, or know which are which; it merely says there must be VPEs if there are DPEs - or indeed, any PEs at all. To be sure, it may be possible to derive some intriguing epistemological or anti-skeptical moral(s) from (b2); but additional argument would be necessary. As it stands, (b2) is consistent with the claim that I can never know some skeptical possibility does not obtain (e.g. - that I am merely dreaming that I am seated by the fire with a piece of paper in my hand).

(ii) Furthermore, Ryle's conclusion is still perfectly compatible with the dreaded possibility that the testimony of our senses is fundamentally unreliable or wildly untrustworthy. Since to say that there cannot be any DPEs unless there are VPEs is not to say that VPEs are the norm (in the sense of being more common than DPEs), Argument (b) does not demonstrate that most perceptual experiences must be veridical; at best, it merely proves that some PEs must be veridical (where 'some,' of course, means 'at least one'). Ryle's argument therefore differs markedly from what we find in Donald Davidson, who contends that massive error about the world is impossible and that most of one's beliefs about the world must be true. ${ }^{18}$ According to Davidson, anyone who understands what a belief is and how beliefs

${ }^{18}$ Cf. Davidson (1977: 201). Austin, too, argues that we must be mostly right about how things are: '[I]t is important to remember that talk of deception only makes sense against a background of general non-deception. (You cannot fool all of the people all of the time.) It must be possible to recognize a case of deception by checking it against more normal ones' (Austin 1962, 11); cf. Austin (1946, 87; 113). 
get their content must appreciate that 'belief is in its nature veridical' (Davidson 1986, 314).

(iii) It does not follow from the claim that not all coins (period) can be counterfeit that there cannot be a time when all coins are counterfeit. Imagine a quasi-Borgesian scenario in which a Moriartylike mastermind instructs his henchmen to take all genuine coins out of circulation, destroy them, and replace them with impeccably crafted counterfeits. Given world enough and time, it is conceivable his underlings should succeed, in which case there would then be no genuine coins, only counterfeits (provided the mint produces no new coins, that is). In the same way, it does not follow from (b2) that anyone now on the scene can boast truly of having a VPE. For instance, it is consistent with (b2) that all VPEs belong to a vanished Golden Age of perceptual excellence enjoyed by our prelapsarian ancestors.

(iv) Furthermore, it does not follow from the claim that there are now some genuine coins in circulation that any of them have come (or ever will come) my way or yours. Similarly, even if we could be sure that there actually are people with VPEs - the happy few, favoured by the inscrutable and capricious gods of perception - (b2) alone can give me no reason to think I am one of the elect. My senses may still be totally unreliable - and so indeed may yours, or those of any individual. That possibility, at any rate, is compatible with Ryle's conclusion.

(v) Suppose, however, that (b2) ruled out the possibility that my senses are all totally unreliable. Yet I am, of course, equipped with five senses. Hence, (b2) seems perfectly compatible with the idea that all my senses save one are totally (i.e. - 100\%) unreliable. All I can conclude, therefore, is that at least one of my senses - but which? - is not globally deceiving me. Note that this does not imply that even one of my senses is reliable, or gets reality right more often than not; all that follows is that on at least one occasion it has gotten (or will get, or is now getting) reality right. This is hardly reassuring news for antiskeptics - to say the least.

\subsection{Whither skepticism?}

So where does this leave the case against skepticism? Let me confine myself to making five remarks: 
(i) We may begin with a simple observation: if $(\mathrm{Q})$ were untrue (i.e. - false or meaningless), then any argument for skepticism which attempted to secure $(\mathrm{C})$ via an appeal to $(\mathrm{Q})$ must be discarded. So much is obvious.

(ii) Yet it is not at all obvious or evident that the Argument from Fallibility - the humble argument with which Ryle began - must appeal to (Q). Consider Descartes'version of that argument, in which there are two main steps. The first step is the move from

(P) Some perceptual experiences are DPEs.

to

(R) Our faculties of sense-perception are not infallible or perfectly reliable.

whereas the second, final step moves from $(\mathrm{R})$ to $(\mathrm{C})$.

(C) Our senses cannot yield knowledge of the external world.

In neither step, it seems, is it necessary to invoke or presuppose (Q). But if a philosopher could consistently accept (b2) and advance the Argument from Fallibility, attacks on (Q) fail to discredit that argument. (I do not deny, of course, that the Argument from Fallibility faces other objections).

(iii) Nevertheless, it might still be urged that Cartesian global skepticism itself somehow depends essentially on (Q). Taken at face value, this claim would appear to rest on a misunderstanding, however; for one can plainly affirm thesis $(\mathrm{C})$ and reject $(\mathrm{Q})$ without logical inconsistency. Rhetorical flourishes and incautious formulations of the 'la vida es sueño' sort aside (with apologies to Calderón de la Barca) ${ }^{19}$ the global skeptic's point is that even if some (or many) of our beliefs happen to be true, none is epistemically justified or war-

${ }^{19}$ A good example can be found in Nagel (1987, 9-10), where the skeptic is presented as somebody who asks how you can possibly know it is not all just a 'giant dream or hallucination, from which you will never wake up' (9), or that your experiences are not 'like a giant dream with no external world outside it' (10). (I hasten to add that Nagel's presentation of skepticism in this introductory book is superb). 
ranted enough to constitute knowledge. As John Greco has astutely observed,

[S]keptical arguments are about knowledge rather than truth. For example, the arguments reconstructed from Descartes and Hume conclude that we lack knowledge of the world, not that the world does not exist. Therefore no argument that establishes that the world exists, or that we dwell in it, or that most of our beliefs are true touches the conclusion that skeptical arguments put forward ... According to these [skeptical] arguments, even if our beliefs are true, they do not amount to knowledge. (Greco 2000, 73)

(iv) However, the challenge to which I have just alluded may take a slightly more subtle form. 'Well and good,' our doughty critic may reply, 'I agree: the skeptical thesis, (C), is consistent with denial of (Q). Nonetheless, does not any argument for (C) need to smuggle in (Q) as a premise (as in the infamous question, 'How do you know it is not all a dream?')? If that is so, and if Ryle is right about (Q), then Ryle has dealt a blow to skepticism after all, has he not?' This, too, seems misguided; for just what entitles the critic to attribute (Q) globally to global skeptics (as it were), regarding it as an indispensable presupposition of absolutely all arguments for (C)? Must the skeptic assume that all of our beliefs could be erroneous? That is very far from clear. Indeed, it would seem enough for him to argue that any belief no matter how propitious or 'ideal' the epistemic circumstances under which it is formed - could turn out to be false. And this is effectively what Descartes does in the First Meditation. Selecting what purports to be a paradigm case of perceptual knowledge (where to say $\mathrm{x}$ is a paradigm case of some phenomenon $\mathrm{P}$ is to say that if $\mathrm{x}$ is not an instance of $\mathrm{P}$, nothing is an instance of $\mathrm{P}$ ), he claims to discover that this is not a case of perceptual knowledge after all; for he says that, on closer inspection, he in fact does not know that he is seated by the fire. (Why not? Because his evidence for that knowledge claim - that is, his sensory experiences at some time, $\mathrm{t}-$ is consistent with the possibility that at $\mathrm{t}$ he is merely dreaming that he is seated by fire). But since this was supposed to be a paradigm case of perceptual knowledge, we can project from it and so arrive at thesis (C), according to which there are no genuine instances of perceptual knowledge.

(v) Finally, some might say that if (Q) is absurd, it is solipsism not skepticism - which is ruled out. Fair enough - provided, that is, 
we grant that a solipsist cannot have any VPEs (and that seems an eminently sensible supposition). Note, however, that anyone who grants this point will have difficulty responding to the first objection to the Argument from Standards outlined above in Section 3.1.

\subsection{Skepticism's undoing: epistemology and the Rylean anticlimax}

So what ultimately makes Ryle's treatment of Cartesian skepticism so unsatisfactory, and how could one do better? By now it will not have escaped the vigilant reader's attention that Ryle's response to skepticism - if that indeed is what it is supposed to be $\mathrm{be}^{20}$ - yields little or no insight into the nature and / or structure of knowledge or justification; nor does it shed light on kindred notions, such as the concepts of belief or truth. In this respect, Ryle's reply contrasts markedly with several deservedly influential - and much more recent - responses to skepticism. To see this, we need only consider some familiar examples:

(a) According to Keith Lehrer (1974) and Nicholas Rescher (1980), the skeptic is correct in asserting that no claims about the world are certain - 'nobody ever knows for certain that anything is true' (Lehrer 1974, 238-239) - but dead wrong to infer from this that no such claims can constitute knowledge. Their complaint, in short, is that skepticism is rooted in 'an improper and incorrect view of the nature of knowledge' (Rescher 1980, xii), according to which knowledge-claims are required to live up to an unattainable standard of absolute certainty.

(b) According to Robert Nozick, '[t]he skeptic asserts we do not know his possibilities do not obtain, and he is right' (Nozick 1981, 201). We do not know we are not BIVs. Nevertheless, full-blown skepticism does not result from this concession unless it is also conceded that knowledge is closed under known logical implication (i.e. - that if $S$ knows that $p$ entails $q$ and $S$ knows that $p$, then $S$ knows that q). But closure is ruled out by Nozick's analysis of knowledge, according to which a belief cannot amount to knowledge unless it 'tracks'

\footnotetext{
${ }^{20}$ See notes 7 and 9 .
} 
the truth (i.e. - if $\mathrm{p}$ were not true, $\mathrm{S}$ would not believe that $\mathrm{p}$; if $\mathrm{p}$ were true, $\mathrm{S}$ would believe it). ${ }^{21}$

(c) According to Richard Rorty (1979), skepticism is invincible so long as we are in the grip of a representationalist picture of thought and language as a medium or tertium quid between mind and world. The neo-pragmatist moral Rorty draws is that we must abandon the idea that the mind is the mirror of nature, and excise the intuition that truth is correspondence with a mind-independent reality to which we have no access independent of our representations. For "once we give up tertia, we give up (or trivialize) the notions of representation and correspondence, and thereby give up the possibility of formulating epistemological skepticism' (Rorty 1986, 139). ${ }^{22}$

(d) Earlier, in Section 4.1, we noted that Donald Davidson maintains that 'belief is in its nature veridical', so that 'most of a person's beliefs must be true' (Davidson 1986, 314). But it is crucial to note Davidson's reply to skepticism does not end with that consoling aperçu. This is because he champions the view that coherence among beliefs constitutes the sole source of epistemic justification: 'nothing can count as a reason for holding a belief except another belief' (Davidson 1986, 310). From the standpoint of his coherentism, then, there is 'a legitimate presumption' that a belief is justified, provided it coheres or fits in well with most of the rest of one's beliefs (Davidson $1986,314){ }^{23}$

(e) Like Davidson, Michael Williams (1996) declares himself an opponent of foundationalism; yet unlike Davidson, he does not think that a coherentist rejoinder to skepticism will suffice. Indeed, Williams concedes that the skeptic is 'conditionally correct' (Williams 1996, 354). In lieu of a refutation, then, Williams seeks to lay bare the presuppositions of skepticism in order to show that 'skeptical arguments derive their force, not from commonsensical intuitions about knowledge, but from theoretical ideas we are by no means bound to

${ }^{21}$ Cf. Warfield (2004) for more on this point. Assessments of Nozick's analysis and its implications can be found in Luper-Foy (1987).

${ }^{22}$ Bernard Williams' last book (2002) includes an illuminating and sharply critical discussion of Rorty's attitude towards truth. Rorty's take on skepticism, truth, and representationalism is examined in some detail in McDermid (2000).

${ }^{23}$ For more on Davidson's reply to skepticism, see Nagel (1999) and Sosa (2003). Those interested in how Davidson's anti-foundationalist epistemology is related to his well-known critique (1974) of the so-called 'third dogma of empiricism' may wish to consult McDermid (2004). 
accept' (Williams 1996, xvii). More specifically, the skeptic is said to take for granted an anti-contextualist doctrine - 'epistemological realism' - according to which every belief of ours possesses 'an inalienable epistemic character which it carries with it wherever it goes and which determines where its justification must finally be sought' (Williams 1996, 116). ${ }^{24}$

(f) David Lewis (1996) proposes the following analysis of knowledge: $\mathrm{S}$ knows that $\mathrm{p}$ just in case ' $\mathrm{S}$ 's evidence eliminates every possibility in which not-P - Psst! - except for those possibilities that we are properly ignoring' (Lewis 1996, 425). According to Lewis' account (Lewis 1996, 426-435), skeptical possibilities, which S's evidence can never eliminate, may be properly ignored in ordinary or everyday contexts, but not in the (extraordinary) philosophical contexts in which the epistemologist is actually considering them or attending to them. As a result, 'ascriptions of knowledge are subtly context-dependent' (Lewis 1996, 420): although skepticism triumphs when we are engaged in epistemological reflection, many knowledgeascriptions may be true outside of such rarefied philosophical contexts. Thus, Lewis opines, 'knowledge is elusive. Examine it, and straightaway it vanishes' (Lewis 1996, 435).

(g) According to John Greco (2000), 'putting skeptics in their place' is a worthwhile philosophical pursuit because the searching analysis of skeptical arguments enhances the sort of understanding epistemologists seek, uncovering 'plausible but mistaken assumptions about knowledge and evidence' (Greco 2000, 3). The skeptic's big mistake, Greco insists, is that of supposing that our beliefs about the world are unjustified because they cannot be inferred from the way things appear to us. This, he pleads, rests on a false assumption; for 'sensory appearances can be good evidence for beliefs about the world, even though such beliefs are not inferred from appearances' (Greco 2000, 169). That reliabilism of the sort Greco himself favours can do justice to this feature of perceptual experience is, he adds, a point in its favour (Greco 2000, 164; cf. 169-170).

To be sure, this is but a small and a highly selective sample of recent responses to skepticism; many other diagnoses have been

\footnotetext{
${ }^{24}$ For a critique of Williams' diagnosis of skepticism, see Stroud (1996).
} 
offered and could have been mentioned. Happily, however, no exhaustive survey of the available theoretical options is necessary here. For my basic point is not that any of (a)-( $g$ ) is actually correct; instead, I offer them as examples of responses to skepticism whose potential philosophical pay-off by far exceeds Ryle's. Note, moreover, that the promised pay-off is not of the same sort in all cases: in some cases such as (a), (b), (d), (f) and (g) $)^{25}$ the response, if correct, would qualify as a solution to a philosophical problem, contributing to the construction of a positive theory of knowledge; in other cases, such as (c) and (e), the reply on offer would effectively amount to a dissolution of some traditional philosophical problem(s) about knowledge, or to the so-called 'death of epistemology' (Williams 1992, 88). But would we gain anything of comparable significance - either for or against epistemology - if Ryle were right about $(\mathrm{Q})$ ? The answer, I submit, is that we would not.

\subsection{A summing up of sorts}

To recapitulate: in this essay, we have (1) expounded Ryle's main argument against (Q); (2) scrutinized two possible sub-arguments for its main premise (i.e. - the Argument from Standards and the Argument from Meaning); (3) found that neither sub-argument is conclusive; (4) compared and contrasted the Argument from Meaning with a recent influential anti-skeptical argument formulated by Hilary Putnam; and (5) seen that (Q)'s rejection poses no significant direct threat to the global skeptic. Indeed, the skeptic emerges virtually unscathed from his tussle with Ryle. Nevertheless, (6) we have seen that - here as elsewhere - reading Ryle with care can refine our sense

\footnotetext{
${ }^{25}$ Note that putting (d) in this first category is somewhat controversial. According to Rorty, for instance, 'Davidson was a bit misleading in suggesting that he was going to show us how coherence yields correspondence. It would have been better to have said that he was going to offer the skeptic a way of speaking which would prevent him from asking his question, than to say he was going to answer that question. It would have been better to tell him that when confrontation goes, so does representation, and thus the picture which made possible both the fears of the skeptic and the hopes of the physicalist, the idealist and the Peircean' (Rorty 1986, 138).
} 
of just what it would take to solve (or dissolve) a seemingly intractable philosophical problem. ${ }^{26}$

Douglas McDermid

Department of Philosophy, Trent University

Peterborough, Ontario

Canada K9J 7B8

dmcdermi@trentu.ca

References

Austin, J.L. 1946. Other Minds. In Austin 1979: 76-116.

1962. Sense and Sensibilia. Oxford: Oxford University Press.

1979. Philosophical Papers. $3^{\text {rd }}$ ed. Oxford: Clarendon Press.

Bird, G. 1992. Ryle, Gilbert. In Dancy and Sosa 1992: 452-454.

Bouwsma, O.K. 1949. Descartes' Evil Demon. In Bouwsma 1965: 85-97.

1965. Philosophical Essays. Lincoln: University of Nebraska Press.

Cavell, S. 1979. The Claim of Reason: Wittgenstein, Skepticism, Morality and Tragedy. Oxford: Oxford University Press.

Dancy, J. and Sosa, E. (eds.) 1992. A Companion to Epistemology. Oxford: Blackwell.

Davidson, D. 1974. On the Very Idea of a Conceptual Scheme. In Davidson 1984: 183-198

1977. The Method of Truth in Metaphysics. In Davidson 1984: 199214.

1984. Inquiries into Truth and Interpretation. Oxford: Clarendon Press.

1986. A Coherence Theory of Truth and Knowledge. In Lepore 1986: 307-19.

Dennett, D. 2000. Re-introducing The Concept of Mind. In Ryle 1949: ix-xix. Grayling, A.C. 1985. The Refutation of Skepticism. LaSalle, IL: Open Court. 1992. Transcendental Arguments. In Dancy and Sosa 1992: 506-509.

Greco, J. 2000. Putting Skeptics in Their Place: The Nature of Skeptical Arguments and Their Role in Philosophical Inquiry. Cambridge: Cambridge University Press.

Hymers, M. 2000. Philosophy and Its Epistemic Neuroses. Boulder, CO: Westerview.

Lehrer, K. 1974. Knowledge. Oxford: Clarendon Press.

Lepore, E. (ed.) 1986. Truth and Interpretation: Perspectives on the Philosophy of Donald Davidson. Oxford: Basil Blackwell.

${ }^{26}$ I wish to extend thanks to anonymous referees for this journal for their very helpful suggestions, and to Marcus Pivato for a brief but timely chat about skepticism. 
Lewis, D. 1996. Elusive Knowledge. In Lewis 1999: 418-445.

1999. Papers in Metaphysics and Epistemology. Cambridge: Cambridge University Press.

Ludwig, K. (ed.) 2003. Donald Davidson. Cambridge: Cambridge University Press.

Luper-Foy, S. (ed.) 1987. The Possibility of Knowledge: Nozick and His Critics. Totowa, N.J.: Rowman \& Littlefield.

MacIntyre, A. (ed.) 1972. Hegel: a collection of critical essays. New York: Anchor Books.

Malcolm, N. 1963. Knowledge and Certainty. Englewood Cliffs, NJ: PrenticeHall.

McDermid, D. 2000. Does Epistemology Rest on a Mistake? Understanding Rorty on Skepticism. Crítica XXXII: 3-42.

- 2004. Is Davidson's Epistemology Coherent? Grazer Philosophische Studien. Vol. 64: 78-107.

Nagel, T. 1986. TheView From Nowhere. New York: Oxford University Press.

1987. What Does it All Mean? A Very Short Introduction to Philosophy. New York: Oxford University Press. 1999. Davidson's New Cogito. In Nagel 2002: 175-186.

2002. Concealment and Exposure: And Other Essays. Oxford: Oxford University Press.

Nozick, R. 1981. Philosophical Explanations. Cambridge, MA: Belknap Press.

Putnam, H. 1981. Reason, Truth and History. Cambridge: Cambridge University Press.

Quinton. A. 1970. Ryle on Perception. In Wood and Pitcher 1970: 105-135.

Rescher, N. 1980. Skepticism: A Critical Reappraisal. Totowa, N.J.: Rowman and Littlefield.

Rorty, R. 1979. Philosophy and the Mirror of Nature. Princeton: Princeton University Press. - 1986. Pragmatism, Davidson, Truth. In Rorty 1991: 126-150.

1991. Objectivity, Relativism, and Truth. Cambridge: Cambridge University Press.

Ryle, G. 1932a. Locke on the Human Understanding. In Ryle 1971a: 126146.

1932b. Systematically Misleading Expressions. In Ryle 1971b: 39-62.

1936. Unverifiability by Me. In Ryle 1971b: 121-130.

1937. Taking Sides in Philosophy. In Ryle 1971b: 153-169.

1938. Categories. In Ryle 1971b: 170-184.

1939. Plato’s Parmenides. In Ryle 1971a: 1-44.

1945. Philosophical Argument. In Ryle 1971b: 194-211.

1946. Knowing How and Knowing That. In Ryle 1971b: 212-225.

1949. The Concept of Mind. London: Penguin, 2000.

1950. The Verification Principle, in Ryle 1971b: 287-293. 
1953a. Thinking. In Ryle 1971b: 294-300. 1953b. Ordinary Language. In Ryle (1971b): 301-318.

1954. Dilemmas. Cambridge: Cambridge University Press.

1954a. Proofs in Philosophy. In Ryle 1971b: 319-325.

1956. Sensation, In Ryle 1971b: 336-349.

1958. A Puzzling Element in the Notion of Thinking. In Ryle 1971b:

391-406.

1960. Letters and Syllables in Plato. In Ryle 1971a: 54-71.

1962a. A Rational Animal. In Ryle 1971b: 415-434.

1962b. Thinking Thoughts and Having Concepts. In Ryle 1971b: 446450.

1965a. The 'Timaeus Locrus.' In Ryle 1971a: 72-88.

1965b. The Academy and Dialectic. In Ryle 1971a: 89-115.

1965c. Dialectic in the Academy. In Ryle 1971a: 116-125.

1966. Plato's Progress. Cambridge: Cambridge University Press.

1968. The Thinking of Thoughts. In Ryle 1971b: 480-496.

1970. Autobiographical. In Wood and Pitcher 1970: 1-15.

1971a. Collected Papers: Volume I: Critical Essays. New York: Barnes and

Noble.

1971b. Collected Papers:Volume II: Collected Essays. New York: Barnes and Noble.

1979. On Thinking. Totowa, N.J. : Rowman and Littlefield.

Sosa, E. 2003. Knowledge of Self, Others, and World. In Ludwig (2003): 163-182.

Stroud, B. 1968. Transcendental Arguments. Journal of Philosophy LXV: 241256.

1984. The Significance of Philosophical Skepticism. Oxford: Oxford University Press.

1996. Epistemological Reflection on Knowledge of the External World. Philosophy and Phenomenological Research 56: 345-358.

Taylor, C. 1972. The Opening Arguments of the Phenomenology. In MacIntyre 1972: 151-187.

Warfield, T. 2004. When Epistemic Closure does and does not Fail: A Lesson From the History of Epistemology, Analysis (forthcoming).

Williams, B. 2002. Truth and Truthfulness: An Essay in Genealogy. Princeton: Princeton University Press.

Williams, M. 1992. Death of Epistemology. In Dancy and Sosa 1992: 88-91. 1996. Unnatural Doubts. Princeton: Princeton University Press.

Wisdom, J. 1936. Philosophical Perplexity. In Wisdom 1964: 36-50. 1946. Philosophy and Psychoanalysis. In Wisdom 1964: 169-181. 1964. Philosophy and Psychoanalysis. Oxford: Basil Blackwell.

Wittgenstein, L. 1969. On Certainty. Trans. D. Paul and G.E.M. Anscombe. New York: Harper Torchbooks.

Wood, O. and Pitcher, G. (eds.) 1970. Ryle: A collection of critical essays. London: Macmillan. 